\title{
USO ANALÍTICO DE TECIDOS E DE EXTRATOS BRUTOS VEGETAIS COMO FONTE ENZIMÁTICA
}

\author{
Orlando Fatibello-Filho*
}

Departamento de Química, Centro de Ciências Exatas e de Tecnologia, Universidade Federal de São Carlos, CP 676, 13560-970

São Carlos - SP

Iolanda da Cruz Vieira

Faculdade de Farmácia e Bioquímica, Universidade de Cuiabá, Av. Beira Rio, 3100, 78015-480 Cuiabá - MT

Recebido em 22/3/01; aceito em 9/8/01

\begin{abstract}
ANALYTICAL USE OF VEGETAL TISSUE AND CRUDE EXTRACT AS ENZYMATIC SOURCE. This article describes the current status of several analytical methodologies using vegetal tissue and crude extracts as enzymatic source. In this divulgation paper the obtention of vegetal crude extract and/or tissue and selected enzymatic procedures are presented emphasizing its characteristics and peculiarities. Examples of many biosensors and/or flow injection procedures using vegetal tissues or crude extracts for the determination of many analytes, such as amines, ascorbic acid, ethanol, glutamate, hydrogen peroxide, oxalic acid, pectins, phenolic compounds and urea of biologic, environmental, food, pharmaceutical and industrial interests are also given and discussed.
\end{abstract}

Keywords: tissue; crude extract; enzyme; biosensor.

\section{INTRODUÇÃO}

A descoberta das enzimas data do século XVIII, quando se iniciaram os estudos sobre digestão dos alimentos ${ }^{1-4}$. No século XIX, Pasteur afirmou que a fermentação era inseparável da célula viva e estabeleceu o conceito de que as enzimas eram células vivas. $\mathrm{Na}$ mesma época, Liebig afirmava que a fermentação era provocada por substâncias químicas ${ }^{1-5}$. A denominação enzima (do grego: "em leveduras") foi dada por Khune em 1878. Em seguida, Buchner acabou com a controvérsia entre Liebig e Pasteur, ao mostrar a possibilidade da fermentação na ausência de células vivas. Os trabalhos de purificação de enzimas começaram depois de $1920^{1-9}$.

Toda enzima possui um centro ativo, local onde se processam as reações com determinados substratos. Esse centro ativo é geralmente constituído de alguns resíduos de aminoácidos da cadeia de proteína e um grupo não-protéico, sendo responsável pela atividade biológica da enzima. Algumas enzimas dependem somente da sua própria estrutura protéica (apoenzima) para exercer sua atividade, enquanto outras necessitam também de um ou mais componentes nãoproteicos chamados de cofatores, que podem ser íons metálicos ou moléculas orgânicas denominadas de coenzimas. Muitas enzimas dependem de ambos. Outras enzimas possuem um grupo prostético que é similar ao cofator, mas está firmemente ligado à apoenzima. $\mathrm{O}$ complexo cataliticamente ativo enzima-cofator é denominado de haloenzima ${ }^{1-9}$.

Enzimas são portanto, na sua grande maioria proteínas que catalisam com grande eficiência as reações biológicas. Essas aceleram várias reações metabólicas importantes para a vida sob condições fisiológicas de $\mathrm{pH}$, temperatura, meio iônico etc. As reações catalisadas por enzimas há muito tempo vêm sendo usadas com diferentes propósitos como a determinação de atividades enzimáticas, inibidores entre outros. Em virtude de sua alta seletividade (em alguns casos especificidade) e poder catalítico, as enzimas vêm sendo muito empregadas em química analítica, bem como na medicina,

"e-mail: bello@dq.ufscar.br agricultura, tecnologia de alimentos e estudos ambientais ${ }^{2}$. O emprego de enzimas purificadas em química analítica pode ser encontrado em excelentes monografias estrangeiras ${ }^{10-26}$ ou nacionais ${ }^{27-29}$. No entanto, há uma carência de monografias de circulação internacional $^{21-24}$ devotadas à utilização de tecidos e/ou extratos vegetais em química analítica e nenhuma na língua portuguesa, tornando assim o presente trabalho de divulgação de extrema importância para as pessoas que trabalham nas áreas mencionadas, além daqueles profissionais que atuam em áreas correlatas.

O Brasil tem uma grande variedade de vegetais que podem constituir em fontes inesgotáveis de enzimas para serem aplicados nas mais diversas áreas do conhecimento. Em química analítica, por exemplo, eles podem ser usados na construção de diversos tipos de biossensores e/ou procedimentos enzimáticos de análise. Há uma tendência recente de utilização de tecidos de vegetais e/ou extratos brutos no lugar de enzimas purificadas na confecção de biossensores e/ou procedimentos enzimáticos de análise ${ }^{21,30-48}$. O uso de extratos brutos e/ou tecidos vegetais pode apresentar em alguns casos, certa desvantagem na seletividade do método analítico, mas por outro lado são extremamente econômicos e geralmente possuem tempo de vida superior àqueles métodos que utilizam enzimas purificadas, visto que estas enzimas naturalmente imobilizadas nas células destes materiais biológicos (habitat natural) são mais estáveis e geralmente possuem o seu cofator disponível.

\section{Obtenção do extrato bruto enzimático}

Há diversos procedimentos descritos na literatura para obtenção de extratos brutos enzimáticos ${ }^{30-44,49,50}$. O procedimento que vem sendo utilizado em nosso grupo de pesquisa ${ }^{30-44}$ é muito simples, rápido, eficiente e a atividade enzimática no extrato é mantida por longos períodos. Exemplificando, a seguir descrever-se-á o procedimento de obtenção do extrato bruto vegetal da abobrinha (Cucurbita pepo) como fonte da peroxidase.

Após lavagem e secagem, $25 \mathrm{~g}$ do tecido vegetal descascado são picados e homogeneizados em um liqüidificador com $100 \mathrm{~mL}$ de tampão fosfato $0,1 \mathrm{~mol} \mathrm{~L}^{-1}$ ( $\mathrm{pH} 6,5$ ), contendo $2,5 \mathrm{~g}$ de agente prote- 
tor (PVPs: polivinilpirrolidonas). Em seguida, o homogenato é filtrado em quatro camadas de gazes e centrifugado a 25000xg (18000 r.p.m.) durante $15 \mathrm{~min}$, a $4{ }^{\circ} \mathrm{C}$. A solução sobrenadante é dividida em diversas alíquotas (e.g. 10), armazenadas em refrigerador a $4{ }^{\circ} \mathrm{C}$ e usadas como fonte enzimática da peroxidase $e^{40,42} \mathrm{em}$ diversos biossensores e/ou procedimentos enzimáticos de análise. Diversos outros extratos brutos como fonte de outras enzimas podem ser obtidos utilizando-se procedimentos similares ${ }^{30-39,41,43,44}$.

\section{Obtenção do tecido vegetal}

O tecido vegetal pode ser obtido na forma de uma fatia do material biológico descascado que é imobilizado na superfície de um eletrodo base potenciométrico, amperométrico entre outros ${ }^{21,23,24}$. Outra possibilidade muito empregada consiste em se utilizar pedaços finamente divididos do material biológico vegetal previamente liofilizado e/ou desidratado ${ }^{30,31,45-48}$. Em sistemas de análises por injeção em fluxo são muito empregados reatores contendo pedaços do material biológico vegetal ${ }^{30-32}$ ou mesmo o material biológico perfurado com o mesmo diâmetro dos tubos de extensão do sistema em fluxo $^{31}$. Nesses casos, a reação enzimática do analito de interesse se processa na interface sólido-solução da amostra (ou solução de referência).

\section{Determinação da atividade e proteína total da enzima}

Como exemplo descrever-se-á o procedimento de determinação da atividade e proteína total da abobrinha como fonte da peroxidase. A atividade da peroxidase foi determinada medindo-se a variação de absorbância em $470 \mathrm{~nm}$ do tetraguaiacol formado na reação enzimática. Nessa determinação são usados $0,2 \mathrm{~mL}$ da solução sobrenadante (homogenato), 2,7 mL da solução de guaiacol $0,05 \mathrm{~mol} \mathrm{~L}^{-1} \mathrm{e} 0,1 \mathrm{~mL}$ da solução de peróxido de hidrogênio $10,3 \mathrm{mmol} \mathrm{L}^{-1}$ em tampão fosfato $0,1 \mathrm{~mol} \mathrm{~L}^{-1}$ (pH 6,5), a $25{ }^{\circ} \mathrm{C}^{40}$. Uma unidade de atividade (unidades/ $\mathrm{mL}$ ) é definida como a quantidade de enzima que causa o aumento de 0,001 unidades de absorbância por minuto nas condições supramencionadas $^{30-44}$. Quando se conhece o valor da absortividade molar do analito ou de um dos produtos da reação enzimática é possível se determinar a atividade internacional $(\mathrm{U})^{1,18}$.

O teor de proteínas totais da solução sobrenadante, por sua vez, pode ser determinado pelo método do biureto ${ }^{51}$ ou de Lowry ${ }^{52}$, empregando-se albumina de soro bovino como padrão. No entanto, diversos outros procedimentos para quantificação de proteína total são usados. Entre eles destacam-se o "Coomassie brilliant blue" BG250 ou reagente de Bradford ${ }^{53}$ e BCA ou reagente de Smith $^{54}$. Recente artigo de divulgação desses procedimentos para determinação de proteínas totais, foi publicado por Zaia et al. ${ }^{55}$.

Um estudo sistemático de obtenção de peroxidase de pêssego (Prunus persica), inhame (Alocasia macrorhiza), mandioca (Manihot utilissima), alcachofra (Cynara scolymus L.), batata doce (Ipomoea batatas L. Lam.), nabo (Brassica campestre ssp. rapifera), rabanete (Armoracia rusticana) e abobrinha (Cucurbita pepo) foi feito por nosso grupo de pesquisa ${ }^{40,42}$. A Tabela 1 apresenta a atividade (unidades $/ \mathrm{mL}$ ), proteína total $(\mathrm{mg} / \mathrm{mL})$ e atividade específica (unidades/ mg de proteína) obtidos para diferentes extratos brutos vegetais. Como pode ser observado nessa tabela, o pêssego (Prunus persica) apresentou a menor atividade específica, enquanto a abobrinha a maior. Além dessas investigações, foram estudados os melhores procedimentos de obtenção de diversos extratos brutos enzimáticos, bem como o tempo de armazenamento a $4{ }^{\circ} \mathrm{C}$.

Os extratos brutos obtidos da abobrinha, rabanete, batata doce $\mathrm{e}$ nabo, em Polyclar SB-100 podem ser armazenados em um refrigerador a $4{ }^{\circ} \mathrm{C}$ e suas atividades determinadas periodicamente durante vários dias. No estudo do tempo de armazenamento desses extratos brutos foi encontrado que a atividade da peroxidase nesses extratos vegetais manteve-se constante por 6 meses e após 10 meses, um decréscimo de atividade de apenas $15-20 \%$ foi observado, mostrando assim boa eficiência de remoção dos substratos naturais desses tecidos foi possível com o emprego de polivinilpirrolidona (PVP) empregado no processo de obtenção dos extratos.

Sabe-se da literatura ${ }^{56-58}$, que a tendência de escurecimento dos tecidos vegetais está relacionada com as reações entre a enzima polifenol oxidase ou peroxidase e os substratos naturais presentes nesses tecidos. Este processo e mais a oxidação promovida pelo oxigênio do ar são os responsáveis pelo decréscimo da atividade enzimática nos extratos brutos. Com o objetivo de minimizar esses efeitos, diversas substâncias protetoras e/ou estabilizadoras como PVPs: Polyclar Super R, Polyclar RJ, Polyclar K-30, Polyclar 10, Polyclar AT, Polyclar R e Polyclar SB-100 foram investigadas. Dessas substâncias, as maiores atividades específicas foram obtidas usando-se Polyclar SB-100 na razão de concentração de 2,5:25,0 m/m (Polyclar:tecido vegetal) ${ }^{30-44}$.

Polyclar SB-100, como as demais polivilpirrolidonas (PVPs), é um polímero de alta massa molar comercializado na forma de pó branco com baixa granulometria. Este polímero tem uma habilidade marcante para remover compostos fenólicos de soluções, devido à sua baixa solubilidade. Esse polímero tem sido usado por diversos pesquisadores ${ }^{30-44,56-58}$ para separar compostos fenólicos naturais de diversos extratos enzimáticos. Este seu bom desempenho é atribuído à formação de pontes de hidrogênio ${ }^{56}$ entre os substratos naturais e o polímero PVP como mostrado na Figura 1. Outras substâncias e polímeros também têm sido usados para remoção dos compostos fenólicos durante a obtenção dos extratos brutos como resinas de troca iônica, L-cisteína, policaprolactam e polietileno glicol ${ }^{56-61}$. Entretanto, estudos desenvolvidos em nosso laboratório ${ }^{30-44}$, mostraram que os PVPs são os melhores agentes protetores.

Apresentar-se-ão a seguir os principais procedimentos enzimáticos descritos na literatura utilizando-se extratos enzimáticos e/ou

Tabela 1. Atividade, proteína total e atividade especifíca da peroxidase encontrada em extrato bruto de diferentes tecidos vegetais

\begin{tabular}{lccc}
\hline Tecido vegetal & $\begin{array}{c}\text { Atividade } \\
\text { (unidades/mL) }\end{array}$ & $\begin{array}{c}\text { Proteína Total } \\
(\mathrm{mg} / \mathrm{mL})\end{array}$ & $\begin{array}{c}\text { Atividade Especifíca } \\
\text { (unidades/mg de proteína) }\end{array}$ \\
\hline Pessêgo & 261,9 & 2,45 & 107 \\
Inhame & 1929 & 5,84 & 303 \\
Mandioca & 1738 & 2,67 & 651 \\
Alcachofra & 8905 & 4,61 & 1932 \\
Batata Doce & 8688 & 3,21 & 2707 \\
Nabo & 4226 & 0,49 & 8624 \\
Rabanete & 3381 & 0,33 & 10245 \\
Abobrinha & 6726 & 0,49 & 13727 \\
\hline
\end{tabular}




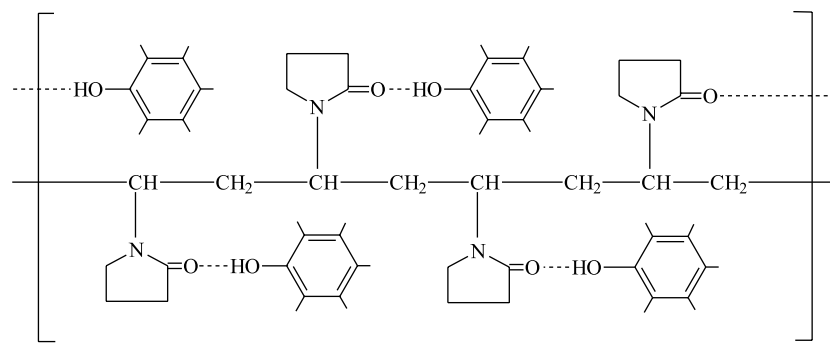

Figura 1. Interação por pontes de hidrogênio entre o polivinilpirrolidona $(P V P)$ e os compostos fenólicos naturais

tecidos de diversos vegetais em ordem alfabética dos analitos (substratos) determinados em diversas amostras de interesse alimentício, ambiental, biológico, farmacêutico e industrial.

\section{PROCEDIMENTOS ANALÍTICOS EMPREGANDO TECIDOS E/OU EXTRATOS BRUTOS DE DIVERSOS VEGETAIS}

\section{Ácido ascórbico}

A grande maioria dos trabalhos descritos na literatura para determinação enzimática de ácido L-ascórbico utilizam a enzima ascorbato oxidase (EC: 1.10.3.3). A ascorbato oxidase catalisa a oxidação do ácido L-ascórbico na presença de oxigênio molecular produzindo o ácido deidroascórbico e água ${ }^{1,21-24}$ (Eq. 1). Essa enzima pode ser encontrada em diversos tecidos de vegetais como pepino, abóbora, repolho, alface, uva e melão.

\section{Ácido L-ascórbico $+1 / 2 \mathrm{O}_{2} \stackrel{\text { Ascorbato oxidase }}{\longrightarrow}$ Ácido deidroascórbico $+\mathrm{H}_{2} \mathrm{O}$}

O ácido L-ascórbico presente em sucos de frutas naturais oxidase rapidamente e, em sucos comercializados, a oxidação desse ácido depende da concentração e tipo de antioxidante utilizado, bem como das características da embalagem e condições de armazenamento do produto. Assim, a determinação e/ou monitoramento da vitamina C (ácido L-ascórbico) nesses e em outros produtos comercializados como complexos multivitamínicos e fármacos em geral é de extrema importância. Por outro lado, muitos produtos disponíveis no mercado usam esse ácido como conservante ou agente de retardamento de diversos processos degradativos ${ }^{1,7,62}$

Há diversos procedimentos enzimáticos para determinação de ácido L-ascórbico descritos na literatura utilizando tecidos e/ou extratos brutos de vegetais como fonte da ascorbato oxidase ${ }^{63-70}$.

Matsumoto et al..$^{63}$ imobilizaram ascorbate oxidase de casca de pepino (Cucumis sativus) com glutaraldeído em uma membrana de colágeno e a afixaram em um eletrodo de oxigênio do tipo Clark. Esse biossensor respondeu linearmente no intervalo de concentra-

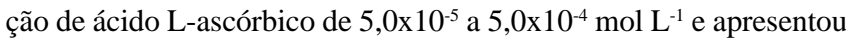
uma precisão menor que $2,3 \%$ na determinação sucessiva $(n=35)$ de ácido L-ascórbico $0,3 \mathrm{mmol} \mathrm{L}^{-1}$. O tempo de vida desse biossensor foi de 3 semanas (aproximadamente 100 determinações/membrana enzimática) e foi utilizado na determinação desse ácido em sucos de tomate, laranja, limão e morango.

Macholan \& Chmelikova ${ }^{64}$ utilizaram fatias com $0,3 \mathrm{~mm}$ de espessura de mesocarpo de abóbora (Cucurbita pepo) ou de pepino (Cucumis sativus) na construção de biossensores para ácido Lascórbico. Esses autores suportaram cada uma dessas fatias sobre uma membrana de PTFE de um eletrodo de oxigênio com o auxílio de uma rede de poliamida e monitoraram o consumo de oxigênio na reação enzimática (Eq. 1) em potencial de - $650 \mathrm{mV}$ vs Ag/AgCl. A curva analítica obtida do decréscimo de corrente, no estado estacionário, em tampão fosfato $(\mathrm{pH} 6,0)$ contendo EDTA $0,5 \mathrm{mmol} \mathrm{L}^{-1}$, foi linear para ácido L-ascórbico no intervalo de concentração de 0,02$0,57 \mathrm{mmol} \mathrm{L}^{-1}$. O tempo de resposta desse biossensor variou de 70 a 90 s e cada fatia de tecido foi empregada em 50-80 determinações. Muitos compostos orgânicos como aminoácidos e glicose não interferiram nesse procedimento amperométrico, permitindo assim aplicálo na determinação desse analito em tabletes de vitaminas e em sucos de diversas frutas. A alta seletividade desse biossensor é atribuída à seletividade da membrana microporosa de PTFE (Teflon) que permite a difusão apenas de moléculas gasosas.

Dois procedimentos amperométricos para determinação de ácido L-ascórbico em sucos de frutas e fluídos biológicos foram propostos por um grupo de pesquisa pernambucano ${ }^{65,66}$. Esses pesquisadores usaram extrato de pepino (Cucurbita maxima) imobilizado com glutaraldeído em uma membrana de um eletrodo de oxigênio ${ }^{65}$, usado como sensor base. Esse biossensor apresentou uma resposta linear de 62,5 a $500 \mu \mathrm{mol} \mathrm{L} \mathrm{L}^{-1}$ de ácido L-ascórbico com um tempo de vida superior a 2 meses. Em um sistema de análise por injeção em fluxo ${ }^{66}$, o extrato bruto de pepino foi imobilizado em esferas de vidro. Um eletrodo de oxigênio foi usado para monitorar o decréscimo linear da concentração de oxigênio na faixa de 0,05-3,00 $\mathrm{mmol} \mathrm{L}^{-1}$ de ácido Lascórbico. Com um reator acoplado nesse sistema foi possível realizar 600 determinações com uma freqüência analítica de $90 \mathrm{~h}^{-1}$.

Esaka et al $^{67}$ imobilizaram ascorbato oxidase de abóbora (Cucurbita pepo) em $6 \% \mathrm{~m} / \mathrm{m}$ de esferas de gel de alginato de cálcio tratado com solução de glutaraldeído $1 \%$ v/v durante $20 \mathrm{~h}$, a $4{ }^{\circ} \mathrm{C}$. O biossensor foi aplicado na determinação de ácido L-ascórbico em sucos de laranja, tomate, uva e morango em um intervalo de concentração de 2 a $20 \mathrm{mg} / \mathrm{mL}$. Testes de adição e recuperação desse ácido nesses sucos de frutas variaram de 81,5 a $89 \%$ e a enzima permaneceu ativa após um período de 3 meses (50 determinações), quando o eletrodo foi armazenado a $15{ }^{\circ} \mathrm{C}$ em um intervalo de $\mathrm{pH}$ de 5 a 7.

Uchiyama et al. ${ }^{68}$ usaram suco de pepino (Cucumis sativus L.) como fonte da enzima ascorbato oxidase como reagente transportador em um sistema de análise por injeção em fluxo e determinaram amperometricamente ácido L-ascórbico. O consumo de oxigênio decresceu linearmente no intervalo de concentração de 5,0x10-4 a 7,0x $10^{-3} \mathrm{~mol} \mathrm{~L}^{-1}$ de ácido L-ascórbico. Os autores enfatizaram a vantagem da não necessidade de purificação da enzima presente no suco de pepino (extrato bruto enzimático). A adição de azida de sódio na solução transportadora, para prevenir a putrefação dessa solução enzimática, pode ser crítica, uma vez que essa substância inibe a atividade da ascorbato oxidase. Desta maneira, o emprego de azida de sódio para estabilizar o extrato bruto de pepino pode comprometer significativamente a atividade da ascorbato oxidase, não sendo assim indicada nesses processos de estabilização. A atividade enzimática permaneceu constante por 8 dias, quando o suco de pepino foi armazenado a $4{ }^{\circ} \mathrm{C}$ e o procedimento em fluxo foi empregado apenas na determinação de ácido L-ascórbico em soluções de referência (padrão). Como discutido, o procedimento de obtenção do extrato enzimático é de extrema importância no desempenho do procedimento analítico. Nesse trabalho os autores deveriam ter investigado outros agentes protetores. Estudos em andamento em nosso laboratório, indicam que as PVPs são muito mais efetivas para a estabilização desse extrato enzimático. Extratos de pepino (Cucumis sativus L.) obtido com o procedimento desenvolvido tem levado a estabilização enzimática por períodos superiores a 2 meses, quando armazenado a $4{ }^{\circ} \mathrm{C}$, mostrando assim ser muito superior aquele empregando a azida de sódio.

Uchiyama \& Umetsu ${ }^{69}$ impregnaram suco de pepino em uma fina camada de feltro de carbono de um eletrodo de oxigênio e deter- 
minaram amperometricamente ácido L-ascórbico em uma faixa linear de concentração de $2,5 \times 10^{-4}$ a $1,6 \times 10^{-3} \mathrm{~mol} \mathrm{~L}^{-1}$. O teor desse ácido em sucos de laranja e de morango foi determinado e o sistema amperométrico necessitou de calibrações periódicas devido ao lixiviamento do suco de pepino do biossensor.

Fernandes et al. ${ }^{70}$ desenvolveram um biossensor potenciométrico imobilizando-se ascorbato oxidase extraída do epicarpo de pepino (Cucumis sativus L.) em um eletrodo de grafite-epóxi por oclusão em uma matriz de polietileno-vinilacetato $40 \% \mathrm{~m} / \mathrm{m}$. O eletrodo apresentou uma linearidade de $8,0 \times 10^{-6}$ a $4,5 \times 10^{-4} \mathrm{~mol} \mathrm{~L}^{-1} \mathrm{e}$ inclinação de $50,3 \pm 0,6 \mathrm{mV} /$ década. O biossensor foi utilizado continuamente durante 15 dias (cerca de 300 determinações) e manteve-se estável por um mês quando armazenado à temperatura de $4{ }^{\circ} \mathrm{C}$. O tempo de resposta foi de 5 min e esse biossensor foi aplicado na determinação dos teores de ácido ascórbico em diversos produtos farmacêuticos.

Uma alternativa inédita explorada pelo nosso grupo de pesquisa para a determinação desse ácido foi desenvolvida recentemente ${ }^{44}$. Trata-se da construção de um eletrodo de pasta de carbono modificado com extrato bruto de abobrinha (Cucurbita pepo) como fonte da enzima peroxidase (PER). Essa enzima na presença de peróxido de hidrogênio $\left(\mathrm{H}_{2} \mathrm{O}_{2}\right)$ catalisa a oxidação da hidroquinona $\left(\mathrm{H}_{2} \mathrm{Q}\right)$ a p-quinona (Q), a qual foi reduzida eletroquimicamente ao reagente (substrato) de partida em potencial de $-0,14 \mathrm{~V}$, fornecendo uma corrente de pico catódica proporcional a sua concentração no intervalo de $2,0 \times 10^{-4}$ a $5,5 \times 10^{-3} \mathrm{~mol} \mathrm{~L}^{-1}$ e limite de detecção de $2,2 \times 10^{-5} \mathrm{~mol} \mathrm{~L}^{-1}$. Desta maneira, quando a solução de ácido L-ascórbico (AA) é adicionada na solução de hidroquinona, esse ácido pode reduzir quimicamente p-quinona a hidroquinona, reagir com oxigênio dissolvido, reduzindo-se a ácido deidroascórbico (ADA) e/ou inibir a enzima peroxidase, decrescendo dessa maneira o pico de corrente proporcionalmente ao aumento de sua concentração. A Figura 2 mostra uma representação esquemática do processo enzimático entre a hidroquinona, peróxido de hidrogênio, ácido L-ascórbico e peroxidase. O biossensor apresentou um bom desempenho analítico, um tempo de vida superior a 7 meses (mais de 900 determinações por quantidade de pasta embutida em cada seringa) e um desvio padrão relativo de $1,3 \%$ para soluções de ácido ascórbico $4,0 \times 10^{-3} \mathrm{~mol} \mathrm{~L}^{-1}$. A alta estabilidade desse e de outros biossensores desenvolvidos em nosso laboratório é atribuída principalmente ao procedimento de obtenção e estabilização dos extratos enzimáticos com polivinilpirrolidonas (PVPs) $)^{30-44}$, que são reconhecidamente um dos compostos mais eficientes empregados na remoção

REDUÇÃO

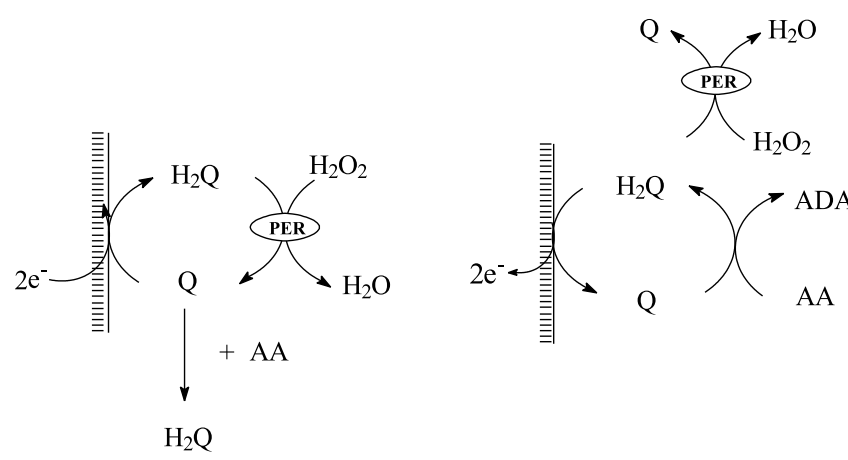

Figura 2. Representação esquemática do mecanismo de redução e de oxidação do processo enzimático entre a hidroquinona $\left(H_{2} Q\right)$, peróxido de hidrogênio $\left(\mathrm{H}_{2} \mathrm{O}_{2}\right)$, ácido ascórbico $(A A)$ e a peroxidase (PER) de extrato bruto de abobrinha (Cucurbita pepo) incorporado na pasta de carbono do biossensor $^{44}$ de substratos naturais ${ }^{56}$, geralmente envolvidos nos processos de diminuição da atividade de diversas enzimas.

\section{Ácido oxálico}

A oxalato oxidase (EC: 1.2.3.4) catalisa a oxidação do ácido oxálico produzindo dióxido de carbono e peróxido de hidrogênio (Eq. 2). Essa enzima é encontrada em polpa de banana, tecido de espinafre e sementes de alguns vegetais ${ }^{21,24}$.

Ácido oxálico $+\mathrm{O}_{2} \stackrel{\text { Oxalato oxidase }}{\longrightarrow} 2 \mathrm{CO}_{2}+\mathrm{H}_{2} \mathrm{O}_{2}$

Oxalato foi determinado potenciometricamente em amostras de urina, plasma e alimentos com um biossensor construído com um eletrodo seletivo a dióxido de carbono ${ }^{71}$ contendo polpa de banana immobilizada. Em um outro trabalho, oxalato foi determinado amperometricamente, monitorando-se o peróxido de hidrogênio ${ }^{72}$ produzido na reação enzimática (Eq. 2) com um biossensor construído com polpa de banana e um eletrodo do tipo Clark $^{73,74}$ polarizado em potencial de $+600 \mathrm{mV}$.

Qin et al..$^{75}$ desenvolveram um biossensor para quantificação de oxalato usando tecido de espinafre empacotado em uma coluna de troca iônica contendo luminol e cobalto(II). As medidas por quimioluminescência em sistema de análise por injeção em fluxo do peróxido de hidrogênio produzido na reação enzimática foram feitas com o emprego de luminol e cobalto(II). A intensidade de emissão da luz foi proporcional à concentração de oxalato de $0,6 \mathrm{a} 100 \mu \mathrm{mol} \mathrm{L} \mathrm{L}^{-1}$. O biossensor apresentou um limite de detecção de $0,2 \mu \mathrm{mol} \mathrm{L}^{-1}$ e foi possível realizar 300 determinações/h.

Fernandes et al. ${ }^{76}$ usaram sementes de sorgo (Sorghum vulgare seeds, variedade BR303) como fonte da enzima oxalato oxidase (E.C: 1.2.3.4.) no desenvolvimento de um novo biossensor para oxalato. O dióxido de carbono produzido na reação enzimática foi monitorado com um eletrodo para $\mathrm{CO}_{2}$ e esse sensor mostrou-se estável durante um mês (200 determinações). O tempo de resposta foi de $60 \mathrm{~s}$ e uma linearidade de 1,0x $10^{-3}$ a $4,0 \times 10^{-3} \mathrm{~mol} \mathrm{~L}^{-1}$ de oxalato foram obtidos. Empregando esse mesmo material biológico, Oliveira-Neto et al. ${ }^{77}$ desenvolveram um procedimento em fluxo com detecção condutométrica para determinação de oxalato em urina. Uma curva analítica para oxalato em concentrações variando de 0,05 a $0,5 \mathrm{mmol} \mathrm{L}^{-1}$ foi obtida e os teores desse analito encontrados em várias amostras empregando esse sistema em fluxo foram comparados com aqueles teores empregando o mesmo sistema em fluxo, mas com enzima pura $(r=0,9995)$.

Fonong ${ }^{71}$ imobilizou fisicamente polpa e casca da banana na extremidade de um eletrodo para dióxido de carbono e em um sensor para peróxido de hidrogênio para monitorar potenciometricamente e amperometricamente oxalato em urina, respectivamente. A resposta potenciométrica obtida foi de $47-50 \mathrm{mV} / \mathrm{dec}$ para $1,0 \times 10^{-4}$ a $2,0 \mathrm{x}$ $10^{-3} \mathrm{~mol} \mathrm{~L}^{-1}$ e uma linearidade de $2,0 \times 10^{-5}-3,0 \times 10^{-4} \mathrm{~mol} \mathrm{~L}^{-1}$ de oxalato foi obtida nas medidas amperométricas.

\section{Álcool etílico}

No procedimento para determinação de álcool etílico usando alcool desidrogenase (EC: 1.1.1.2), um biossensor pode monitorar a espécie eletroativa NADH produzida na reação enzimática (Eq. 3), enquanto que o consumo de oxigênio na reação NADH (Eq. 4) pode ser monitorado com um eletrodo para oxigênio do tipo Clark $^{18}$.

$$
\begin{aligned}
& \mathrm{C}_{2} \mathrm{H}_{5} \mathrm{OH}+\mathrm{NAD}^{+} \stackrel{\text { Alcool desidrogenase }}{\longrightarrow} \mathrm{NADH}+\mathrm{CH}_{3} \mathrm{CHO}+\mathrm{H}^{+} \\
& \mathrm{NADH} \mathrm{NAD}^{+}+2 \mathrm{e}^{-}+\mathrm{H}^{+}
\end{aligned}
$$


Diversos procedimentos alternativos para determinação de álcoois, aldeídos e ácidos carboxílicos de cadeia curta usando álcool desidrogenase purificada podem ser encontrados em monografias especializadas ${ }^{18,21-24}$, como espectrofotométricos, fluorimétricos, condutométricos e quimioluminescentes.

Ozsoz \& Wang ${ }^{78}$ construíram um biossensor de pasta de carbono contendo semente de tomate como fonte da alcool desidrogenase e determinaram alguns álcoois de cadeia curta. As sementes secas de tomate foram imersas em água por $24 \mathrm{~h}$, maceradas e suas cascas removidas. A parte interna dessas sementes foi misturada convenientemente com $0,6 \mathrm{~g}$ de pó de grafite e $0,4 \mathrm{~g}$ de óleo mineral. Uma parte dessa pasta foi então embutida na extremidade inferior de um tubo de vidro ( $3 \mathrm{~mm}$ de d. i.) e o contato elétrico externo foi feito com um fio de cobre. Com uma célula eletroquímica contendo como eletrodo indicador o biossensor de tecido, um eletrodo auxiliar de platina e um eletrodo referência de $\mathrm{Ag} / \mathrm{AgCl}$, esses autores determinaram os teores de etanol e álcool alílico.

Outras fontes alternativas da enzima alcool desidrogenase que podem ser empregadas no desenvolvimento de biossensores e/ou métodos enzimáticos de análise incluem as sementes de algodão $(\text { Gossypium hirsutum cv. Siokra) })^{79}$, de girassol (Helianthus annus) ${ }^{80}$, soja (Glycine max) ${ }^{81}$, pimentão (Capsicum annuum $)^{82}$, amendoim (Arachis hypogaea $^{83}$, tabaco (Nicotiana sylvestris) ${ }^{84}$, tecidos de morango (Fragaria xananassa Duch) ${ }^{85}$, oliva (Olea europaea) $)^{86} \mathrm{e}$ beterraba (Beta vulgaris) $)^{87}$. Essas alternativas de emprego desses materiais biológicos são de extrema importância para as indústrias sucro-alcoleiras, uma vez que o monitoramento dos teores de etanol nos processos fermentativos pode levar a maior produtividade dessa substância importante para a economia nacional.

\section{Aminas}

As amina oxidases são grupos de enzimas que catalizam a oxidação de aminas primárias, diaminas e poliaminas pelo oxigênio molecular aos aldeídos correspondentes, peróxido de hidrogênio e amônia, como representado pela Equação $5^{88}$ :

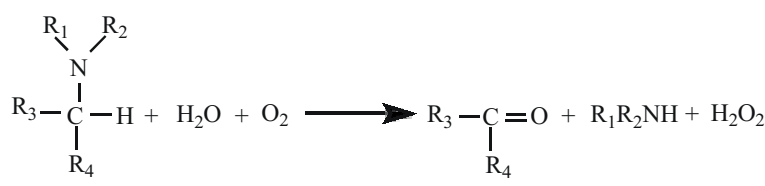

onde $\mathrm{R}_{1}, \mathrm{R}_{2}$ representam $\mathrm{H}$ ou grupo alquila e $\mathrm{R}_{3}$ e $\mathrm{R}_{4}, \mathrm{H}$, alquila ou arila.

São conhecidos dois tipos principais de amina oxidases ${ }^{89}$, aqueles contendo cobre (Cu-AOs; EC: 1.4.3.6) e amino oxidases contendo flavina (FAD-AOs; EC: 1.5.3.3).

Em 1948, Werle et al..$^{90}$ observaram pioneiramente a atividade da amino oxidase em extratos de plantas. Desde então, a amina oxidase foi encontrada nas seguintes espécies de plantas: aveia (Avena sativa), pepino (Cucumis sativas), soja (Glicine max), semente de ervilha (Pisum sativum), folha de Onobrychis viciifolia, semente e folha de Vicia faba, entre outras ${ }^{91-94}$. Esses materiais biológicos supramencionados podem ser empregados na construção de biossensores e/ou procedimentos enzimáticos de análise para determinação de diversas aminas de interesse, constituindo assim num nicho importante de investigação.

Sebela et al..$^{95}$ estudaram a amino oxidase de ervilhas por polarografia de pulso diferencial. Polarogramas dessa enzima em tampão fosfato $50 \mathrm{mmol} \mathrm{L}^{-1}(\mathrm{pH}$ 7) e aqueles obtidos após reação da amino oxidase separadamente com os reagentes dietilditiocarbamato, dietilpirocarbonato e borohidreto de sódio, indicaram que a quinona (cofator) e íons cobre ligados ao centro ativo, são os centros de oxidação-redução dessa metaloproteína. Entretanto, muitos estudos visando melhor compreensão da atividade catalítica dessa enzima poderão ser ainda explorados.

Wimmerova \& Macholan ${ }^{96}$ construíram um biossensor amperométrico para diversas aminas primárias e secundárias, imobilizando tecido de ervilha (Pisum sativum), como fonte da enzima amino oxidase em um eletrodo de pasta de carbono. Considerando as fontes vegetais disponíveis no Brasil da enzima amino oxidase e o pequeno número de biossensores descritos na literatura especializada, há certamente muitas possibilidades de construção de novos biossensores para várias aminas em amostras diversas.

\section{Compostos fenólicos}

Bourquelot \& Bertrand em 1895 observaram o aparecimento de um composto escuro no cogumelo na presença da tirosina. Em 1896 foi atribuído o nome de tirosinase a enzima presente no cogumelo, sendo assim chamada porque o primeiro substrato usado foi a tirosina $a^{97-107}$.

A tirosinase (EC: 1.14.18.1) é também conhecida como polifenol oxidase, catecol oxidase, catecolase e cresolase. Essa enzima catalisa a oxidação tanto de monofenóis (e.g. tirosina, fenol, p-cresol) (Eq. 6) como difenóis (e.g. catecol, L-dopa, dopamina, adrenalina) (Eq.7 $)^{97-107}$. É largamente distribuída na natureza e encontrada nos tecidos de kiwi, arroz, abacate, pêra, maçã, morango, uva, folha de espinafre, palmito, banana, batata inglesa, batata doce, pêssego, manga, berinjela, inhame entre outros ${ }^{47-50,108-126}$.

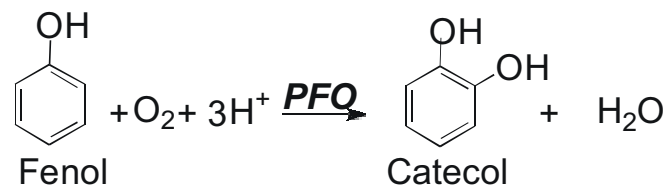

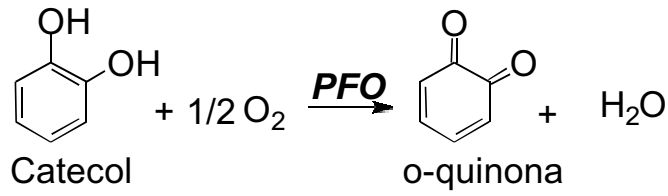

Como mencionado para o cogumelo, essa enzima é responsável pelo escurecimento enzimático de muitos vegetais e frutas quando cortados e expostos ao ar. Este escurecimento é causado pela ação dessa enzima com os compostos fenólicos naturais e o oxigênio atmosférico que são oxidados a o-quinona, que em seguida pode se polimerizar e formar as melaninas ${ }^{101-104}$. Nos tecidos vegetais, a enzima PFO esta localizada nos cloroplastos ${ }^{103,104}$ e sua concentração (atividade) no tecido vegetal depende do local do plantio, período da colheita, espécie e do estado de amadurecimento deste, sendo menor em frutos ou vegetais não-amadurecidos ${ }^{103,104}$.

Schubert et al. ${ }^{127}$ utilizaram tecido de beterraba (Beta vulgaris altissima) acoplado em um eletrodo de oxigênio e determinaram tirosina em um intervalo de concentração de $3,0 \times 10^{-7}$ a $9,0 \times 10^{-4} \mathrm{~mol} \mathrm{~L}^{-1}$. $\mathrm{O}$ biossensor também apresentou resposta para alguns compostos fenólicos como fenol, p-clorofenol e o-cresol.

Uchiyama et al. ${ }^{128}$ desenvolveram um biossensor amperométrico seletivo a catecol utilizando entre 40 e $60 \mathrm{mg}$ de tecido de folhas de espinafre (Spinacea oleracea) picadas e suportadas por uma membrana de diálise (Technicon "C"). Esse biossensor apresentou um

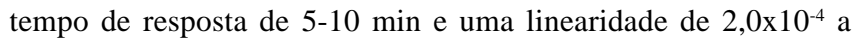


8,0x $10^{-4} \mathrm{~mol} \mathrm{~L}^{-1}$ de catecol. Tecido de espinafre também foi usado por Zhihong et al. ${ }^{129} \mathrm{em}$ um biossensor de pasta de carbono para dopamina. A linearidade obtida foi de $1,7 \times 10^{-6}$ a $1,6 \times 10^{-4} \mathrm{~mol} \mathrm{~L}^{-1}$ e o limite de detecção foi de $7,1 \times 10^{-7} \mathrm{~mol} \mathrm{~L}^{-1}$.

Navarante et al. ${ }^{130}$ desenvolveram um eletrodo de pasta de carbono contendo $9 \% \mathrm{~m} / \mathrm{m}$ de tecido de berinjela, $41 \% \mathrm{~m} / \mathrm{m}$ de Nujol e $50 \% \mathrm{~m} / \mathrm{m}$ de pó de grafite para determinação de catecol em concentrações da ordem de micromolar. Observou-se um tempo de vida de 3 semanas e uma linearidade de $5,0 \times 10^{-6}$ a $5,5 \times 10^{-5} \mathrm{~mol} \mathrm{~L}^{-1}$ de catecol.

Botrè et al. ${ }^{131}$ construíram um biossensor para catecol, usando uma fatia fina (espessura de $100 \mu \mathrm{m}$ e diâmetro de $10 \mathrm{~mm}$ ) de tecido de batata (Solanum tuberosum) afixada com uma membrana de diálise diretamente em um eletrodo de oxigênio. Esse biossensor respondeu linearmente no intervalo de concentração de $2,5 \times 10^{-5}$ a $2,3 \times 10^{-4} \mathrm{~mol} \mathrm{~L}^{-1}$ de catecol. Também usando tecido de batata, Uchiyama et al. ${ }^{132} \mathrm{de}-$ senvolveram um biossensor para catecol, usando ácido ascórbico na solução tampão fosfato. Esse biossensor apresentou um limite de

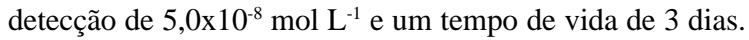

Forzani et al. ${ }^{133}$ construíram um biossensor de pasta de carbono sensível a dopamina, com $24,4 \% \mathrm{~m} / \mathrm{m}$ de tecido de batata e $42,6 \%$ $\mathrm{m} / \mathrm{m}$ de acetileno de carbono e Nujol. A reação foi monitorada amperometricamente em $0,05 \mathrm{~V}$ vs ECS em solução tampão fosfato (pH 6,75) e esse biossensor apresentou um limite de detecção de $2,5 \times 10^{-6} \mathrm{~mol} \mathrm{~L}^{-1}$.

Biossensores para catecolaminas usando tecidos de batata, cogumelo e abacate diretamente acoplados na superfície de um eletrodo de oxigênio foram construídos por Mazzei et al. ${ }^{134}$ Esses eletrodos de tecidos vegetais apresentaram uma linearidade de $2,5 \times 10^{-5} \mathrm{a}$ $1,9 \times 10^{-4} \mathrm{~mol} \mathrm{~L}^{-1}$ e um limite de detecção de $1,0 \times 10^{-5} \mathrm{~mol} \mathrm{~L}^{-1}$.

Sidwell \& Rechnitz ${ }^{135}$ desenvolveram um biossensor de tecido de banana e o chamaram de bananatrodo, sensível a dopamina. Esse biossensor apresentou um tempo de resposta de 1-3 min, linearidade de $2,0 \times 10^{-4}$ a $1,2 \times 10^{-3} \mathrm{~mol} \mathrm{~L}^{-1}$ e tempo de vida de duas semanas.

Wang \& $\operatorname{Lin}^{136}$ construíram um biossensor de pasta de carbono sensível a dopamina, L-dopa e adrenalina com tecido de banana, pó de grafite e Nujol. Aplicou-se um potencial constante de - 0,2 V vs $\mathrm{Ag} / \mathrm{AgCl}$ nesse eletrodo e as correntes medidas foram proporcionais à concentração desses analitos. $\mathrm{O}$ eletrodo enzimático apresentou um tempo de resposta de $12 \mathrm{~s}$, limite de detecção de $1,3 \times 10^{-6} \mathrm{~mol} \mathrm{~L}^{-1} \mathrm{e}$ linearidade de 5 a $90 \mu \mathrm{mol} \mathrm{L} \mathrm{L}^{-1}$ para de dopamina. Wang \& Brennsteiner ${ }^{137}$ usaram tecido de banana e cogumelo e construíram um microeletrodo modificado de pasta de carbono. Esse biossensor amperométrico apresentou um limite de detecção de 4,0x10-7 $\mathrm{mol} \mathrm{L}^{-1}$ para dopamina. Quando esse biossensor foi armazenado a $4{ }^{\circ} \mathrm{C}$ por um período de 30 dias, sua resposta decresceu $20 \%$ daquela obtida no primeiro dia (inicial).

Chen \& Tan ${ }^{138-140}$ imobilizaram pó de diferentes tecidos vegetais (batata, banana, cogumelo e maçã) em uma membrana de policarbonato com e sem a presença de Nafion. Essa membrana quando seca foi fixada em um eletrodo de oxigênio e a partir do consumo de $\mathrm{O}_{2}$ foi determinada a concentração de dopamina.

Yifeng et al. ${ }^{141}$ construíram um biossensor usando tecido de cogumelo e tecido de banana, resina epóxi e pó de grafite. O potencial de trabalho foi de - $0,2 \mathrm{~V}$ vs $\mathrm{Ag} / \mathrm{AgCl}$. O eletrodo contendo tecido de cogumelo apresentou uma faixa linear de $1,2 \times 10^{-5}$ a $5,0 \times 10^{-2} \mathrm{~mol} \mathrm{~L}^{-1}$ para catecol e aquele contendo tecido de banana, um intervalo linear de $1,2 \times 10^{-5}$ a $3,0 \times 10^{-2} \mathrm{~mol} \mathrm{~L}^{-1}$ de catecol. O tempo de vida desse biossensor foi de aproximadamente 1 mês.

Ozsoz et al. ${ }^{142}$ usaram tecido de cogumelo, ftalocianina de cobalto, pó de grafite e Nujol e construíram um biossensor para compostos fenólicos (catecol, fenol e dopamina). O biossensor apresentou um limite de detecção de $7,5 \times 10^{-6} \mathrm{~mol} \mathrm{~L}^{-1}$ e tempo de resposta de $60 \mathrm{~s}$.
Diversos biossensores enzimáticos, de tecidos de beterraba ${ }^{127}$, berinjela ${ }^{130}$ e cogumelo ${ }^{143}$ para determinação de L-dopa, dopamina e adrenalina foram também propostos. As principais desvantagens desses eletrodos que empregam fatias de tecido vegetal são o alto tempo de resposta e a baixa reprodutibilidade das características analíticas entre eletrodos. Nesse último caso, é muito difícil reproduzir com boa exatidão as dimensões das fatias do tecido e também o posicionamento exato da fatia de tecido vegetal no sensor. No caso específico dos biossensores envolvendo a polifenol oxidase, há um agravante adicional da formação de melaninas nos interstícios do tecido usado no biossensor. A formação desses produtos de condensação de quinonas leva a aumentos consideráveis do tempo de resposta dos biossensores e principalmente à diminuição da sensibilidade do mesmo, uma vez que o polímero formado (melaninas) vai bloqueando os interstícios da camada biológica do biossensor, dificultando a difusão do analito e também causa diminuição da atividade catalítica da enzima naturalmente imobilizada no tecido vegetal.

Lima et al. ${ }^{45}$ desenvolveram um procedimento usando um reator com tecido de coco e determinaram catecol em águas de rio e águas residuárias. O procedimento foi adaptado em fluxo e 60-90 determinações/h foram feitas. Uma linearidade de $5,0 \times 10^{-6}$ a $8,0 \times 10^{-4} \mathrm{~mol}$ $\mathrm{L}^{-1}$ e um limite de detecção de $2,0 \times 10^{-6} \mathrm{~mol} \mathrm{~L}^{-1}$ para catecol foram obtidos. Em um outro trabalho, Lima et al..$^{46}$ empregaram tecido da Latania sp. como fonte da enzima polifenol oxidase na construção de um biorreator e também de um biossensor de pasta de carbono para quantificação de diversos compostos fenólicos. Esse fruto é encontrado em abundância, principalmente no nordeste brasileiro, podendo assim ser obtido gratuitamente e empregado no desenvolvimento de metodologias analíticas, por pesquisadores da região. Assim, as praias seriam o almoxarifado contendo vastíssimas quantidades de frascos (cocos) contendo a polifenol oxidase imobilizada.

Fatibello-Filho \& Vieira ${ }^{47,48}$ desenvolveram um biossensor de tecido de batata doce (Ipomoea batatas (L.) Lam) contendo como agente aglutinante parafina ${ }^{47}$ e ácido esteárico ${ }^{48}$ e determinaram hidroquinona em cremes dermatológicos em metanol. Um estudo sistemático do desempenho desse biossensor em função do tipo de aglutinante e também da polaridade do solvente orgânico empregado (e.g. metanol, acetonitrila, etanol, acetona, 1-propanol, tetrehidrofurano, butanol, clorofórmio e 2-propanol) são discutidos e comparados com biossensores empregando enzimas comercializadas. Um artigo de revisão sobre a biocatálise em meios aquo-restritos aplicados em química analítica publicado por Lima \& Angnes ${ }^{144}$ trata com muita propriedade o assunto e deve ser consultado, especialmente aquele descrevendo os biossensores em fase orgânica.

São poucos os métodos enzimáticos descritos na literatura usando extrato bruto de tecidos vegetais. O primeiro trabalho usando extrato bruto vegetal foi desenvolvido por Uchiyama et al. ${ }^{145}$. Esses pesquisadores determinaram dopamina, catecol e adrenalina usando extrato bruto de banana ou espinafre (fonte da enzima polifenol oxidase) como reagente transportador em um sistema de análise por injeção em fluxo. Uma melhor estabilidade do sistema foi obtida com o suco de espinafre e a linearidade deste procedimento foi de $1,0 \times 10^{-4}$ a $6,0 \times 10^{-3} \mathrm{~mol} \mathrm{~L}^{-1}$ para dopamina, $2,0 \times 10^{-4}$ a $8,0 \times 10^{-3} \mathrm{~mol} \mathrm{~L}^{-1}$ para catecol e $2,0 \times 10^{-4}$ a $6,0 \times 10^{-3} \mathrm{~mol} \mathrm{~L}^{-1}$ para adrenalina.

Signori \& Fatibello-Filho ${ }^{30-32}$ desenvolveram um biossensor amperométrico para compostos fenólicos imobilizando extrato bruto de inhame (Alocasia macrohiza) com glutaraldeído diretamente em uma membrana de um eletrodo de oxigênio. $\mathrm{O}$ biossensor apresentou uma resposta linear para pirogalol, catecol, fenol e p-cresol nas faixas de concentrações de $2,5 \times 10^{-5}$ a $8,0 \times 10^{-5} \mathrm{~mol} \mathrm{~L}^{-1}, 1,0 \times 10^{-5}$ a $8,5 \times 10^{-5} \mathrm{~mol} \mathrm{~L}^{-1}, 1,0 \times 10^{-5}$ a $9,0 \times 10^{-5} \mathrm{~mol} \mathrm{~L}^{-1}$ e $1,0 \times 10^{-5}$ a $1,0 \mathrm{x}$ $10^{-4} \mathrm{~mol} \mathrm{~L}^{-1}$, respectivamente. Nesse caso, o tempo de resposta foi de aproximadamente $3 \mathrm{~min}$, muito menor que o tempo de resposta da- 
queles biossensores de tecido vegetal afixado em um sensor para oxigênio.

Vieira \& Fatibello-Filho ${ }^{34,35}$ construíram um biossensor amperométrico para compostos fenólicos usando extrato bruto da batata doce (Ipomoea batatas (L.) Lam.) imobilizados em um eletrodo de oxigênio. Esse biossensor apresentou uma resposta linear para catecol, pirogalol, fenol e p-cresol no intervalo de concentração de $2,0 \times 10^{-5}$ a $4,3 \times 10^{-4} ; 2,0 \times 10^{-5}$ a $4,3 \times 10^{-4} ; 2,0 \times 10^{-5}$ a $4,5 \times 10^{-4} ; 2,0 \times 10^{-5}$ a $4,5 \times 10^{-4} \mathrm{~mol} \mathrm{~L}^{-1}$, respectivamente. O tempo de resposta foi de $3-5$ min e o tempo de vida foi de 15 dias (250 determinações/ membrana enzimática).

Caruso et al. ${ }^{33,41}$ construíram um biossensor de pasta de carbono modificado com extrato bruto de cará (Dioscorea bulbifera) sensível a catecol, dopamina e adrenalina. Foram usados $65 \%(\mathrm{~m} / \mathrm{m})$ de pó de grafite contendo 40 unidades da enzima PFO e $35 \%(\mathrm{~m} / \mathrm{m})$ de Nujol. A enzima polifenol oxidase oxida esses analitos à quinona, dopaminacromo e adrenocromo e, a redução eletroquímica desses compostos foram acompanhadas nos potenciais de $+0,1 ;+0,14$ e $0,14 \mathrm{~V} v s$ ECS, respectivamente. As curvas analíticas obtidas de correntes de pico catódicas e as concentrações destes analitos foram de $2,5 \times 10^{-4}$ a $1,5 \times 10^{-3} \mathrm{~mol} \mathrm{~L}^{-1}$ para catecol, $2,0 \times 10^{-3}$ a $8,0 \times 10^{-3} \mathrm{~mol} \mathrm{~L}^{-1}$ para dopamina e $2,0 \times 10^{-4}$ a $1,2 \times 10^{-3} \mathrm{~mol} \mathrm{~L}^{-1}$ para adrenalina. $\mathrm{O}$ biossensor foi aplicado para determinação de catecol em águas residuárias e catecolaminas (dopamina e adrenalina) em formulações farmacêuticas.

Fatibello-Filho \& Vieira ${ }^{36}$ desenvolveram um procedimento de análise por injeção em fluxo com detecção espectrofotométrica para determinação de L-dopa e carbidopa em formulações farmacêuticas. Como solução carregadora foi usada 120 unidades $/ \mathrm{mL}$ do extrato bruto da PFO. O limite de detecção foi de $1,5 \times 10^{-5}$ e $2,0 \times 10^{-5} \mathrm{~mol} \mathrm{~L}^{-1}$ para L-dopa e carbidopa, respectivamente. As recuperações desses analitos em três formulações farmacêuticas variaram de 98,6 a 106,3\%. Em um outro trabalho ${ }^{38}$, esses pesquisadores desenvolveram um método espectrofotométrico em fluxo para a determinação de compostos fenólicos em águas residuárias usando a mesma solução transportadora. Esse procedimento em fluxo apresentou uma linearidade de $2,0 \times 10^{-4} \mathrm{a}$ $2,0 \times 10^{-3} \mathrm{~mol} \mathrm{~L}^{-1}$ de catecol e um limite de detecção de $1,0 \times 10^{-5} \mathrm{~mol} \mathrm{~L}^{-1}$. Um procedimento espectrofotométrico manual, rápido, preciso e de baixo custo foi também desenvolvido ${ }^{39}$ para determinação de metildopa, dopamina e adrenalina em formulações farmacêuticas empregando como fonte da enzima PFO extrato bruto de batata doce (Ipomoea batatas (L.) Lam.). Como pode ser constatado nesses artigos publicados, o emprego das PVPs no preparo dos extratos brutos confere maior estabilidade enzimática em comparação com aqueles obtidos sem o emprego desse agente protetor.

\section{Glutamato}

O primeiro biossensor de tecido vegetal foi construído em 1981 por Kuriyama \& Rechnitz ${ }^{146}$. Esses pesquisadores usaram uma fatia de tecido de abóbora, fonte da enzima L-glutamato decarboxidase (EC: 4.1.1.15) acoplado em um eletrodo para $\mathrm{CO}_{2}$. Essa enzima catalisa a reação de oxidação de glutamato, como mostrada na Eq. 8. A linearidade obtida foi de $2,0 \times 10^{-4}$ a $1,3 \times 10^{-2} \mathrm{~mol} \mathrm{~L}^{-1}$ para glutamato e um tempo de vida de 7 dias foi observado.

Glutamato $\stackrel{\text { Glutamato oxidase }}{\longrightarrow}$ 4-aminobutirato $+\mathrm{CO}_{2}$

A reprodutibilidade da construção desse eletrodo, como discutido, fica comprometida, uma vez que é muito difícil reproduzir a mesma camada de tecido vegetal (fatia de tecido da abóbora). Uma maneira de se aumentar a reprodutibilidade de construção desse biossensor pode ser alcançada trabalhando-se com o pó do tecido desidratado (tamanho de partículas da ordem de $100 \mathrm{~nm}$ ) ou empregar extrato bruto do vegetal.

\section{Pectinas}

A pectinesterase (pectina metoxilase; EC: 3.1.1.11) catalisa a hidrólise da ligação éster de substâncias pécticas (remoção do grupos metoxilas) produzindo álcool metílico e ácido pectínico ou péctico $^{1}$ (Eq. 9).
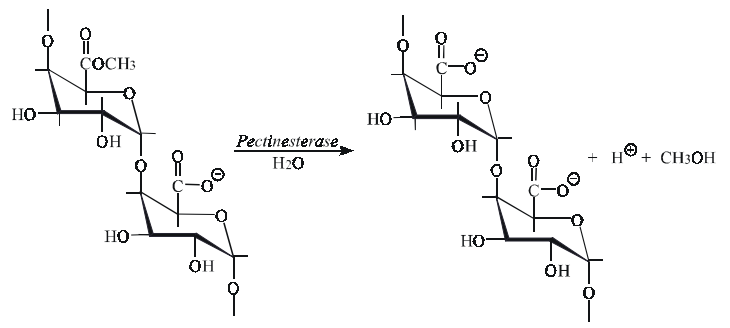

Essa enzima é encontrada em diversos tecidos vegetais como tomate, laranja, limão, cenoura e mamão. Possui grande importância na indústria de alimentos, uma vez que é usada para facilitar a filtração e/ou clarificação de sucos de frutas e também na produção de pectinas.

Horie \& Rechnitz ${ }^{147}$ usaram uma fatia de casca de laranja e construíram um biossensor de pasta de carbono para determinação de pectina. A pectina foi monitorada em $0,9 \mathrm{~V} v s \mathrm{Ag} / \mathrm{AgCl}$ e a linearidade foi de 0,1 a $0,9 \mathrm{~g} / \mathrm{L} \mathrm{em} \mathrm{pH} 7,5$.

Dois procedimentos espectrofotométricos para pectina foram propostos na literatura ${ }^{148,149}$ baseados no monitoramento do metanol formado na reação enzimática (Eq. 9) utilizando-se os reagentes cromogênicos azul de bromotimol ${ }^{148}$ e 3-metilbenzotiazol-2-onahidrazona $^{149}$, respectivamente. Outra possibilidade seria a detecção do ácido péctico em uma solução contendo íons cálcio(II) em excesso, com um biossensor construído com um eletrodo íon-seletivo a cálcio.

\section{Peróxido de hidrogênio}

A peroxidase (PER; EC: 1.11.1.7) é encontrada em tecidos de vegetais e animais. Schönbein em 1855, usando extratos de plantas com peróxido de hidrogênio e guaiacol observou que um composto de coloração intensa era formado. Linossier em 1898 isolou esta enzima e chamou de peroxidase ${ }^{150-154}$. A PER catalisa a oxidação pelo peróxido de hidrogênio de alguns substratos como mono e difenóis, polifenóis, aminofenóis, entre outros. É conhecida como uma enzima termoestável que pode ter sua atividade regenerada após tratamento térmico. Diversas são as fontes dessa enzima como pêssego, tomate, soja, rabanete, abobrinha, nabo e aspargo ${ }^{150-155}$.

Diversos procedimentos são citados na literatura para determinação de peróxido de hidrogênio usando diferentes tecidos vegetais, como aspargo, uva, abacaxi, rabanete, nabo, alface, entre outros e extrato bruto de abobrinha, como fonte da enzima peroxidase ${ }^{40,47,48,155-157}$.

Oungpipat et al. ${ }^{155}$ usaram tecido de aspargo e desenvolveram um biossensor amperométrico sensível a peróxido de hidrogênio. Ferroceno foi usado como mediador de elétrons e o produto formado foi monitorado em 0,0 $\mathrm{mV}$ vs ECS. Esse biossensor apresentou um tempo de resposta de $2 \mathrm{~s}$, desvio padrão relativo menor do que $1 \%$ e limite de detecção de $4,0 \times 10^{-7} \mathrm{~mol} \mathrm{~L}^{-1}$.

Navarante \& Rechnitz ${ }^{156}$ construíram um biossensor de pasta de carbono usando tecido de tabaco. O tempo de vida desse eletrodo foi maior que cinco meses, o tempo de resposta de $2 \mathrm{~s}$ e o limite de detecção de $7,5 \times 10^{-7} \mathrm{~mol} \mathrm{~L}^{-1}$. 
Tecido de kohlrabi (Brassica oleracea caulo-rapa) também foi usado pelo grupo do Prof. Rechnitz ${ }^{157}$ como fonte da peroxidase. Usando tecido desse vegetal e ferroceno para facilitar a transferência de elétrons entre o analito e o biossensor esses pesquisadores construíram um biossensor de pasta de carbono para determinação de peróxido de hidrogênio. O eletrodo enzimático apresentou um tempo de resposta de 2,6 s em uma ampla faixa de $\mathrm{pH}(5,0$ a 7,4).

Vieira \& Fatibello-Filho ${ }^{40}$ desenvolveram um procedimento em FIA para determinação de peróxido de hidrogênio em água oxigenada de uso farmacêutico e água de piscina usando extrato bruto de abobrinha como fonte da enzima peroxidase na solução transportadora. A Eq. 10 apresenta a reação entre guaiacol e peróxido de hidrogênio catalisada pela peroxidase.

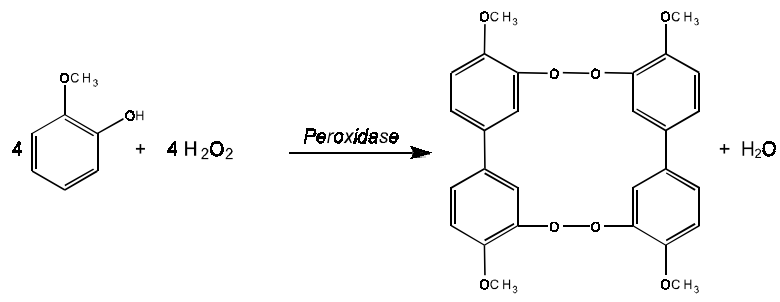

Esses autores trabalharam com uma concentração constante de guaiacol e monitoraram espectrofotometricamente em $470 \mathrm{~nm}$ a concentração de tetraguaiacol formado na reação enzimática. $\mathrm{O}$ método proposto apresentou uma linearidade de $1,6 \times 10^{-5}$ a $6,6 \times 10^{-4} \mathrm{~mol} \mathrm{~L}^{-1} \mathrm{e}$ um limite de detecção de $2,1 \times 10^{-6} \mathrm{~mol} \mathrm{~L}^{-1}$ para peróxido de hidrogênio.

\section{Uréia}

A urease (EC: 3.5.1.5) obtida do feijão de soja foi a primeira enzima a ser cristalizada em 1926, por J. B. Sumner ${ }^{1-3}$. Essa enzima catalisa a hidrólise da uréia, formando o íon amônio e bicarbonato, como mostrada na Equação 11. Encontra-se principalmente em sementes de feijão.

$$
\begin{array}{rl}
\left(\mathrm{NH}_{2}\right)_{2} \mathrm{CO}+\mathrm{H}_{2} \mathrm{O} \stackrel{\text { Urease }}{\longrightarrow} \underset{\mathrm{OH}^{-} \downarrow \uparrow \mathrm{H}^{+}}{2} & 2 \mathrm{NH}_{4}^{+}+\mathrm{HCO}_{3}^{-} \\
& \mathrm{NH}_{3}+\mathrm{H}_{2} \mathrm{O}
\end{array}
$$

Eletrodos contendo urease imobilizada em sensores empregados em medidas de $\mathrm{pH}$, como o de vidro e de antimônio-óxido de antimônio ${ }^{24}$ foram construídos para a determinação de uréia em urina. Outros biossensores propostos envolvem o monitoramento do dióxido de carbono produzido na reação enzimática com um eletrodo potenciométrico de membrana de Teflon ${ }^{24}$.

Arnold \& Glazier ${ }^{158}$ desenvolveram um biossensor para uréia usando tecido de feijão como fonte da urease. Graciliano-Neto et $a l .{ }^{159}$ também construíram um biossensor para uréia, e empregaram tecido de feijão (Canavalia-maritima) imobilizado com glutaraldeído em uma membrana de PVC na superfície de um eletrodo sensível a amônia. Em um outro trabalho, Silva et al. ${ }^{160}$ determinaram uréia em análise por injeção em fluxo monitorando o cátion amônio formado na reação enzimática entre uréia e extrato bruto de feijão (Canavalia ensiformis) com um eletrodo tubular potenciométrico.

Um sistema de análise por injeção em fluxo com detecção condutométrica foi construído por Faria et al. ${ }^{161}$ para a determinação de uréia em soro humano. Esses pesquisadores usaram feijão de soja (Canavalia ensiformis $d c$ ) como fonte natural da enzima urease imobilizado em uma coluna de $3 \mathrm{~cm}$ (reator enzimático). Os íons amônio gerados enzimaticamente causaram um aumento da condutância da solução receptora que foi proporcional à concentração de uréia na amostra. Esse procedimento apresentou uma freqüência analítica de 40 determinações/h.

Graciliano-Neto et al. ${ }^{162}$ construíram um biorreator contendo $120 \mathrm{mg}$ de Canavalia brasiliensis imobilizados com glutaraldeído e o adaptaram em um sistema em fluxo com detecção potenciométrica. Os íons amônio produzidos na reação enzimática foram convertidos a amônia em uma solução alcalina que permeou através de uma membrana de politetrafluoroetileno. Esse procedimento em fluxo apresentou uma curva analítica de $2,5 \times 10^{-4}$ a $2,5 \times 10^{-3} \mathrm{~mol} \mathrm{~L}^{-1}$ e foi empregado com sucesso na quantificação de uréia em fertilizantes.

Um sistema de análise por injeção em fluxo para determinação de uréia empregando um reator enzimático contendo tecido de soja e quimioluminescência foi descrito por Qin et al. ${ }^{163}$. Uma faixa linear de concentração de uréia entre $4-400 \times 10^{-6} \mathrm{~mol} \mathrm{~L}^{-1}$ com limite de detecção de $2 \times 10^{-6} \mathrm{~mol} \mathrm{~L}^{-1}$ foram obtidos e o emprego de uma resina de troca aniônica separou algumas substâncias interferentes da urina.

\section{CONSIDERAÇÕES FINAIS}

Esse artigo de divulgação apresentou alguns procedimentos analíticos empregando tecidos e/ou extratos brutos vegetais para determinação de vários analitos de interesse alimentício, ambiental, farmacêutico, industrial e tecnológico. Como pode ser observado, tratam-se de procedimentos enzimáticos relativamente simples, mas de extremo interesse. Em virtude da grande biodiversidade encontrada no Brasil, há certamente um número muito grande de procedimentos analíticos que poderão ser desenvolvidos de interesse naquelas áreas supramencionadas, especialmente aqueles para detecção de substâncias em tempo real, uma tendência que vem sendo observada na química analítica moderna. Como esses materiais biológicos vegetais são de baixo custo e geralmente mais estáveis que as enzimas purificadas, o conhecimento e o emprego de tais materiais em diversas metodologias analíticas vem ganhando muito prestígio e importância nos últimos tempos.

Uma outra possibilidade que se apresenta é a obtenção de enzimas purificadas obtidas no próprio laboratório do pesquisador para posterior emprego em biossensores e/ou procedimentos enzimáticos de análise. Gaspar et al. ${ }^{164-166}$ empregaram biossensores construídos com peroxidases obtidas e purificadas de tabaco (Nicotiana sylvestris) e batata doce (Ipomoea batatas) e fizeram um estudo comparativo empregando esses biossensores ${ }^{164}$ com enzimas comerciais e aquelas obtidas no laboratório.

\section{AGRADECIMENTOS}

Os autores agradecem ao $\mathrm{CNPq}$ as bolsas de produtividade recebidas e também a FAPESP, PADCT/CNPq e FINEP os recursos financeiros para o desenvolvimento dos trabalhos do grupo, especialmente aqueles de construção de biossensores e procedimentos em fluxo envolvendo extratos ou tecidos vegetais.

\section{REFERÊNCIAS}

1. Whitaker, J. R.; Principles of Enzymology for the Food Sciences; Marcel Dekker; New York, 1972.

2. Dixon, M.; Webb, E. C.; Enzymes; Academic Press; New York, 1979.

3. Palmer, T.; Understanding Enzymes; John Wiley \& Sons; New York, 1985.

4. Lehninger, A. L.; Princípios de Bioquímica; Sarvier; São Paulo, 1986, p 154.

5. Gava, A. J.; Princípios de Tecnologia de Alimentos; Nobel; São Paulo, 1988, pp. 95.

6. Bobbio, F. O.; Bobbio, P. A.; Introdução à Química de Alimentos; Varela; São Paulo, 1989, pp. 109. 
7. Voet, D.; Voet, J. G.; Biochemistry; John Wiley \& Sons; New York, 1995, pp. 332.

8. Stryer, L.; Biochemistry; W. H. Freeman and Company, New York, 1995, pp. 181.

9. Devlin, T. M.; Textbook of Biochemistry with Clinical Correlations; John Wiley \& Sons; New, 1997, pp. 127.

10. Guilbault, G. G.; Anal. Chem. 1966, 38, 527R.

11. Weetall, H. H.; Anal. Chem. 1974, 46, 602A.

12. Kennedy, J. F.; White, C. A.; Melo, E. H. M.; Chimic. 1988, maggio, 21.

13. Scheller, F.; Shubert, F.; Pfeiffer, D.; Hintsche, R.; Dransfeld, I.; Renneberg, R.; Wollenberger, U.; Riedel, K.; Pavlova, M.; Kühn, M.; Müller, H. G.; Tan, P. M.; Hoffmann, W.; Moritz, W.; Analyst 1989, 114, 653.

14. Blum, L. J.; Coulet, P. R.; Analusis 1992, 20, M34.

15. Scouten, W. H.; Luong, J. H. T.; Brown, R. S.; Tibtech. 1995, 13, 178.

16. Chibata, I.; Immobilized Enzymes: Research and Development; John Wiley \& Sons; New York, 1978.

17. Trevan, M. D.; Immobilized Enzymes: An Introduction and Applications in Biotechnology ; John Wiley \& Sons; New York, 1980.

18. Guilbault, G. G.; Analytical Uses of Immobilized Enzymes; Marcel Dekker; New York, 1984.

19. Laskin, A. I.; Enzymes and Immobilized Cells in Biotechology; The Benjamin/ Cummings Publishing Company; New Jersey, 1985.

20. Martinek, K.; Mozhaev, V. V.; Immobilization of Enzymes: An Approach to Fundamental Studies in Biochemistry, Meister, A., Ed.; John Wiley \& Sons; New York, 1985, pp. 179.

21. Arnold, M. A.; Rechnitz, G. A.; Biosensors Based on Plant and Animal Tissue. In Biosensors: Fundamentals and Applications; Turner, A. P. F.; Karube, I.; Wilson, G. S.; Eds.; Oxford University Press; New York, 1987, p. 30-59.

22. Guilbault, G. G.; Mascini, M.; Analytical Uses of Immobilized Biological Compounds for Detection, Medical and Industrial Uses; Reidel Publishing Company; Boston, 1988.

23. Maholán, L.; Biocatalytic Membrane Electrodes. In Bioinstrumentation and Biosensors, Wise, D. L.; Ed.; Marcel Dekker; New York, 1991, p. 329-377.

24. Guilbault, G. G.; Suleiman, A. A.; Fatibello-Filho, O.; Nabirahni, M. A.; Immobilized Bioelectrochemical Sensors. In Bioinstrumentation and Biosensors; Wise, D. L.; Ed.; Marcel Dekker; New York, 1991, p. 659-692.

25. Bickerstaff, G. F.; Immobilization of Enzymes and Cells; Humana Press; New Jersey, 1997.

26. Lam, S.; Malikin, G.; Analytical Applications of Immobilized Enzyme Reactors; Blackie Academic \& Professional; New York, 1994.

27. Oliveira-Neto, G.; Yamanaka, H.; Quim. Nova 1988, 11, 432.

28. Fatibello-Filho, O.; Capelato, M. D.; Quim. Nova 1992, 15, 28.

29. Rosatto, S. S.; Freire, R. S.; Duran, N.; Kubota, L. T.; Quim. Nova 2001, 24, 77.

30. Signori, C. A.; Fatibello-Filho, O.; Quim. Nova 1994, 17, 38.

31. Perone, C. A. S.; Tese de Doutorado; UNESP; Araraquara, SP, 1996.

32. Fatibello-Filho, O.; Perone, C. A. S.; The Third World Congress on Biosensors, 1-3 june, New Orleans, USA, 1994, pp. 2.19.

33. Caruso, C. S.; Dissertação de Mestrado; UFSCar, São Carlos, SP, 1997.

34. Vieira, I. C.; Tese de Doutorado; UFSCar, São Carlos, SP, 1997.

35. Vieira, I. C.; Fatibello-Filho, O.; Anal. Lett. 1997, 30, 895.

36. Fatibello-Filho, O.; Vieira, I. C.; Analyst 1997, 122, 345.

37. Fatibello-Filho, O.; Vieira, I. C.; Anal. Chim. Acta 1997, 354, 51.

38. Vieira, I. C.; Fatibello-Filho, O.; Anal. Chim. Acta 1998, 366, 111.

39. Vieira, I. C.; Fatibello-Filho, O.; Talanta 1998, 46, 559

40. Vieira, I. C.; Fatibello-Filho, O.; Analyst 1998, 123, 1809.

41. Caruso, C. S.; Vieira, I. C.; Fatibello-Filho, O.; Anal. Lett. 1999, 132, 39.

42. Vieira, I. C.; Fatibello-Filho, O.; Angnes, L.; Anal. Chim. Acta 1999, 398, 145 .

43. Vieira, I. C.; Fatibello-Filho, O.; Anal. Chim. Acta 1998, 399, 287.

44. Vieira, I. C.; Fatibello-Filho, O.; J. Braz. Chem. Soc. 2000, 4, 412

45. Lima, A. W. O.; Nascimento, V. B.; Pedrotti, J. J.; Angnes, L.; Anal. Chim. Acta 1997, 354, 325.

46. Lima, A. W. O.; Vidsiunas, E. K.; Nascimento, V. B.; Angnes, L.; Analyst 1998, 123, 2377.

47. Vieira, I. C.; Fatibello-Filho, O.; Talanta 2000, 52, 412.

48. Fatibello-Filho, O.; Vieira, I. C.; Fresenius J. Anal. Chem. 2000, 368, 338.

49. Lourenço, E. J.; Leão, J. S.; Neves, V. A.; J. Sci. Food Agric. 1990, 52, 249.

50. Montgomery, M. W.; Sgarbieri, V. C.; Phytochem. 1975, 14, 1245.

51. Gornall, A. G.; Bardawill, C. J.; David, M. M.; J. Biol. Chem. 1949, 177, 751.

52. Lowry, O. H.; Rosebrough, N. J.; Farr, A. L.; Randall, R. J.; J. Biol. Chem. 1951, 193, 265.

53. Bradford, M. M.; Anal. Biochem. 1976, 72, 248.

54. Smith, P. K.; Krohn, R. I.; Hermanson, G. T.; Mallia, A. K.; Gartner, F. H.; Provenzano, M. D.; Fujimoto, E. K.; Goeke, N. M.; Olson, B. J.; Klenk, D. C.; Anal. Biochem. 1985, 150, 76.
55. Zaia, D. A. M.; Zaia, C. T. B. V.; Lichtig, J.; Quim. Nova 1998, 21, 787

56. Andersen, R. A.; Sowers, J. A.; Phytochem. 1968, 7, 293

57. Loomis, W. D.; Methods in Enzymology 1969, 13, 555.

58. Loomis, W. D.; Battaile, J.; Phytochem. 1966, 5, 423.

59. Lourenço, E. J.; Neves, V. A.; Silva, M. A. J.; J. Agric. Food Chem. 1992, 40, 2369.

60. Sanderson, G. W.; Biochim. Biophys. Acta 1964, 92, 622

61. Park, E. Y.; Luh, B. S.; J. Food Sci. 1985, 50, 678.

62. Diniz, M. C. T.; Dissertação de Mestrado; UFSCar; São Carlos; SP, 1998

63. Matsumoto, K.; Yamada, K.; Osajima, Y.; Anal. Chem. 1981, 53, 1974.

64. Macholan, L.; Chmelikova, B.; Anal. Chim. Acta 1986, 185, 187.

65. Marques, E. T. A.; Lima, J. L.; Applied Biochem. and Biotechnol. 1992, $32,73$.

66. Marques, I. D. H. C.; Marques, E. T. A.; Silva, A. C.; Ledinghan, W. M., Melo; E. H. M. Silva; V. L.; Lima, J. L.; Applied Biochem. and Biotechnol. 1994, 44, 81 .

67. Esaka, M.; Suzuki, K.; Kubota, K.; Agric. Biol. Chem. 1985, 49, 2955.

68. Uchiyama, S.; Tofuku, Y.; Suzuki, S.; Anal. Chim. Acta 1988, 208, 291.

69. Uchiyama, S.; Umetsu, Y.; Anal. Chim. Acta 1991, 225, 53.

70. Fernandes, J. C. B.; Kubota, L. T.; Oliveira-Neto, G.; Anal. Chim. Acta 1989, 385, 3 .

71. Fonong, T.; Anal. Chim. Acta 1986, 186, 301.

72. Assolant-Vinet, C. H.; Bardeletti, G.; Coulet, P. R.; Anal. Lett. 1987, 20, 513.

73. Nabi Rahni, M. A .; Guilbault, G. G.; Oliveira-Neto, G.; Anal. Chem. 1986, $58,523$.

74. Bradley, C. R.; Rechnitz, G. A.; Anal. Lett. 1986, 19, 151.

75. Qin, W.; Zhang, Z. J.; Peng, Y. Y.; Li, B. X.; Anal. Communic. 1999, 36, 337.

76. Fernandes, J. R.; Oliveira-Neto, G.; Kubota, L. T.; Tubino, M.; Anal. Communic. 1996, 33, 397.

77. Oliveira-Neto, G.; Tubino, M.; Godinho, O. E. S.; Kubota, L. T.; Fernandes, J. R.; J. Braz. Chem. Soc. 1997, 8, 47.

78. Ozsoz, M.; Wang, J.; Electroanal. 1991, 3, 655.

79. Millar, A. A.; Oliver, M. R.; Dennis, E. S.; Biochem. Genetics 1994, 32, 279.

80. Torres, A. M.; Genetics 1974, 77, S65.

81. Tang, S. L.; Chang, H. H.; J.; Agricult. Assoc. China 1990, 150, 22.

82. Smith, P. T.; Cobb, B. G.; Physiologia Plantarum 1991, 82, 433.

83. Chung, S. Y.; Vercellotti, J. R.; Sanders, T. H.; Chem. Markers for Processed and Stored Foods 1996, 631, 179.

84. Zarsky, V.; Chomatova, S.; Tupy, J.; Biologia Plantarum 1994, 36, 53.

85. Mitchell, W. C.; Jelenkovic, G.; J. Am. Soc. Horticult. Science 1995, 120, 798.

86. Salas, J. J.; Sanchez, J.; Phytochem. 1998, 48, 35.

87. Konovalov, A. A.; Genetika 1994, 30, 945.

88. Robinson, D. S.; Eskin, N. A. M.; Oxidative Enzymes in Foods; Elsevier Applied Science; New York, 1985, pp. 93.

89. Medda, R.; Padiglia, A.; Floris, G.; Phytochem. 1995, 39, 1.

90. Werle, E.; Raub, A.; Biochem. Z. 1948, 318, 538.

91. Smith, T. A.; Phytochem. 1977, 16, 1647.

92. Percival, F. W.; Purves, W. K.; Plant Physiol. 1974, 54, 601.

93. Suzuki, Y.; Plant Cell Physiol. 1973, 14, 413

94. Mann, P. J. G.; Biochem. J. 1961, 79, 623.

95. Sebela, M.; Studnickova, M.; Wimmerova, M.; Bioelectrochem. and Bioenerg. 1996, 41, 173.

96. Wimmerova, M.; Macholan, L.; Chemicke Listy 1996, 90, 725.

97. Zawistowski, J.; Biliaderis, C. B.; Eskin, N. A. M., Polyphenol Oxidase. In Oxidative Enzymes in Food, Robinson, D. S.; Eskin, N.A.M.; Eds.; Elsevier Applied Science; New York, 1991, pp. 217.

98. Nelson, J. M.; Dawson, C. R.; Tyrosinase. In Advances in Enzymology and Related Subjects of Biochemistry, Nord, F. F; Werkman, C. H.; Eds.; Interscience Publishers; New York, 1944, vol. IV, p. 99-152.

99. Lerner, A. B.; Metabolism of Phenylalanine and Tyrosinase. In Advances in Enzymology and Related Subjects of Biochemistry, Nord, F. F.; Ed.; Interscience Publishers; New York, 1953, vol. XIV, p. 73-128.

100. Sizer, I. W.; Oxidation of Proteins by Tyrosinase and Peroxidase. In Advances in Enzymology and Related Subjects of Biochemistry, Nord F. F.; Ed.; Interscience Publishers; New York, 1953, vol. XIV, p. 129-161.

101. Mason, H. S.; Comparative Biochemistry of the Phenolase Complex. In Advances in Enzymology and Related Subjects of Biochemistry, Nord, F. F.; Ed.; Interscience Publishers; New York, 1955, vol. XVI, p. 105-184.

102. Mathew, A. G.; Parpia, H. A. B.; Food Browning as a Polyphenol Reaction. In Advances in Food Research, Chichester, C. O.; Mrak, E. M.; Stewart, G. F.; Eds.; Academic Press; New York, 1971, vol. XIX, p. 75-145.

103. Dawson, C. R.; Tarpley, W. B.; Copper Oxidases. In The Enzymes Chemistry and Mechanism of Action, Sumner, J. B.; Myrback, K.; Eds.; Academic Press; New York, 1951, vol.II, p. 455-491. 
104. Dawson, C. R.; Magee, R. J.; Plant Tyrosinase (Polyphenol oxidase). In Methods in Enzymology; Colowick, S. P.; Kaplan, N. O.; Eds.; Academic Press; New York, 1955, vol.II, p. 817-826.

105. Anderson, J. W.; Phytochem. 1968, 7, 1973.

106. Mayer, A. M.; Harel, E.; Phytochem. 1979, 18, 193.

107. Mayer, A. M.; Phytochem. 1987, 26, 11.

108. Park, E. Y.; Luh, B. S.; J. of Food Science 1985, 50, 678.

109. Owusu-Ansah, Y. J.; J. Agric. Food Chem. 1989, 37, 901.

110. Tate, J. N.; Luh, B. S.; York, G. K.; J. Food Sci. 1964, $29,829$.

111. Zhou, P.; Smith, N. L.; Lee, C. Y.; J. Agric. Food Chem. 1993, 41, 532.

112. Janovitz-Klapp, A.; Richard, F.; Nicolas, J.; Phytochem. 1989, 28, 2903.

113. Wesche-Ebeling, P.; Montgomery, M. W.; J. Food Science 1990, 55, 1315

114. Valero, E.; Varon, R.; Garcia-Carmona, F.; J. Food Science 1988, 53, 1482.

115. Chilaka, F. C.; Anosike, E. O.; Egbuna, P. C.; J. Sci. Food Agric. 1993, $61,125$.

116. Oda, Y.; Kato, H.; Isoda, Y.; Takahashi, N.; Yamamoto, T.; Takada, Y.; Kudo, S.; Agric. Biol. Chem. 1989, 53, 2053.

117. Padron, M. P.; Lozano, J. A.; González, A. G.; Phytochem. 1975, 14, 1959.

118. Knapp, F. W.; J. Food Sci. 1965, 30, 930.

119. Sakamura, S.; Shibusa, S.; Obata, Y.; J. Food Sci. 1966, 31, 317.

120. Okamoto, A.; Imagawa, H.; Arai, Y.; Ozawa, T.; Agric. Biol. Chem. 1988, $52,2215$.

121. Anosike, E. O.; Ayaebene, A. O.; Phytochem. 1982, 21, 1889.

122. Park, Y. K.; Sato, H. H.; Almeida, T. D.; Moretti, R. H; J. Food Sci. 1980, 45, 1619.

123. Batistuti, J. P.; Lourenço, E. J.; Food Chem. 1985, 18, 251

124. Patil, S. S.; Zucker, M.; J. Biol. Chem. 1965, 240, 3938.

125. Alberghina, F. A. M.; Phytochem. 1964, 3, 65.

126. Hyodo, H.; Uritani, I.; J. Biochem. 1965, 58, 388

127. Shubert, F.; Wollenberger, U.; Scheller, F.; Biotechnology Lett. 1983, 5, 239.

128. Uchiyama, S.; Tamata, M.; Tofuku, Y.; Suzuki, S.; Anal. Chim. Acta 1988, 208, 287.

129. Zhihong, L.; Wenjian, Q.; Meng, W.; Anal. Lett. 1992, 25, 1171.

130. Navaratne, A.; Lin, M. S.; Rechnitz, G. A.; Anal. Chim. Acta 1990, 237, 107.

131. Botrè, F.; Mazzei, F.; Lanzi, M.; Lorenti, G.; Botrè, C.; Anal. Chim. Acta 1991, 255, 59

132. Uchiyama, S.; Hasebe Y.; Shimizu H.; Ishihara H.; Anal. Chim. Acta 1988, $276,341$.

133. Forzani, E. S.; Rivas, G. A.; Solis, V. M.; J. Electroanal. Chem. 1995, 382, 33.

134. Mazzei, F.; Botrè, F.; Lanzi, M.; Lorenti, G.; Botrè, C.; Sensors and Actuators B 1992, 7, 427.

135. Sidwell, J. S.; Rechnitz, G. A.; Biotechology Lett. 1985, 7, 419.
136. Wang, J.; Lin, M. S.; Anal. Chem. 1988, 60, 1545.

137. Wang, J.; Brennsteiner, A.; Anal. Lett. 1988, $21,1773$.

138. Chen, Y.; Tan, T. C.; Sensors and Actuators B 1995, $28,39$.

139. Chen, Y.; Tan, T. C.; Talanta 1995, 42, 1181.

140. Tan, T.C.; Chen, Y.; Sensors Actuators B 1994, 12, 10

141. Yifeng, T.; Anal. Lett. 1993, 26, 1557.

142. Ozsoz, M.; Erdem, A.; Kilinc, E.; Gorgunnec, L.; Electroanal. 1996, 8, 147.

143. Campanella, L.; Beone, T.; Sammartino, M. P.; Tomassetti, M.; Analyst 1993, 118, 979 .

144. Lima, A. W. A.; Angnes, L.; Quim. Nova 1999, 22, 229.

145. Uchiyama, S.; Tofuku, Y.; Suzuki, S.; Anal. Chim. Acta 1988, 208, 291.

146. Kuriyama, S.; Rechnitz, G. A.; Anal. Chim. Acta 1981, 131, 91

147. Horie, H.; Rechnitz, G. A.; Anal. Chim. Acta 1995, 306, 123.

148. Hagerman, A. E.; Austin, P. J.; J. Agric. Food Chem. 1986, 34, 440.

149. Pifferi, P. G.; Malacarne, A.; Lanzarini, G.; Casoli, U.; Chem. Mikrobiol. Technol. Lebensm. 1985, 9, 65.

150. Campa, A.; Biological Roles of Plant Peroxidases: Know and Potential Function. In Peroxidase in Chemistry and Biology, Everse, K.; Grisham, M.B.; Eds.; CRC Press; New York, 1991, vol. II, pp. 25.

151. Vámos-Vigyázo, L.; CRC Critical Reviews in Food Sci. and Nutrition 1981, $15,49$.

152. Bruemmer, J. H.; Roe, B.; Bowen, E. R; J. Food Sci. 1976, 41, 186.

153. Kahn, V.; Gold Smidt, S.; Amir, J.; Granit, R.; J. Food Sci. 1981, 46, 756.

154. Burnette, F. S.; J. Food Science 1977, 42, 1.

155. Oungpipat, W.; Alexander, P. W.; Southwell-Keely, P.; Anal. Chim. Acta 1995, 309, 35.

156. Navaratne, A.; Rechnitz, G. A.; Anal. Chim. Acta 1992, 257, 59.

157. Chen, L.; Lin, M. S.; Hara, M.; Rechnitz, G. A.; Anal. Lett. 1991, $24,1$.

158. Arnold, M. A.; Glazier, M. A.; Biotechnol. Lett. 1984, 6, 313.

159. Graciliano-Neto, O.; Godinho, O. E. S.; Aleixo, L. M.; Silva, V. L.; Electroanal. 1994, 6, 593.

160. Silva, F. V.; Nogueira, A. R. A.; Souza, G. B.; Reis, B. F.; Araújo, A. N.; Montenegro, M. C. M. B. S.; Lima, J. L. F. C.; Talanta 2000, 53, 331.

161. Faria, L. C.; Pasquini, C.; Oliveira-Neto, G.; Analyst 1991, 116, 357.

162. Júnior, L. R.; Oliveira-Neto, G.; Lima, J. L. F. C.; Montenegro, M. C. B. S. M.; Silva, V. L.; Anal. Sci. 1997, 13, 589.

163. Qin, W.; Zhang, Z.; Peng, Y., Anal. Chim. Acta 2000, 407, 81.

164. Gaspar, S.; Popescu, I. C.; Gazaryan, I. G.; Bautista, A. G.; Sakharov, I. Y.; Mattiasson, B.; Csöregi, E.; Electrochim. Acta. 2000, 46, 255.

165. Gaspar, S.; Zimmermann, H.; Gazaryan, I. G.; Csöregi, E.; Schuhmann, W.; Electroanalysis 2001, 13, 284.

166. Gaspar, S.; Habermuller, K.; Csöregi, E.; Schuhmann, W.; Sensors and Actuators B 2001, 72, 63 . 